\title{
Gender Differences in Scratch Game Design*
}

\author{
Hui-mei Justina Hsu \\ Department of Applied Informatics, Fo Guang University Yilan, Jiaosi 26247, Taiwan \\ hmhsu@mail.fgu.edu.tw
}

\begin{abstract}
The purpose of this project is to understand elementary school students' preferences in interactive game design. By examining the processes of elementary school students using Scratch to design and create games, this study intends to investigate gender differences in terms of computer literacy, multimedia application, codes and game design preferences in order to understand the factors influencing students' achievement and motivation in computer science. This study was carried out in the setting of a Scratch contest. In total, 46 contest participants were recruited. Questionnaires on programming concepts derived from computing thinking and analysis of student works were utilized as the major research method. The research results indicate that (1) girls had significantly better knowledge of counting loops than boys; (2) boys used significantly more built-in costumes than girls; (3) boys used more diverse sensing blocks than girls; (4) boys incorporated more game design mechanisms than girls; (5) girls were likely to incorporate positive feedback, while boys were likely to incorporate negative feedback and both positive and negative feedback.
\end{abstract}

Index Terms - Game design, Gender and technology, Children's programming, Computational thinking

\section{Introduction}

In recent years, computational thinking has been considered as an important aspect of computer literacy. Computational thinking is a way of thinking that models the logic and processing of computers [1]. Computational thinking is decomposed into data collection, data analysis, data representation, problem decomposition, abstraction, algorithm $\&$ procedure, automation, simulation, and parallelization [2]. It is regarded as an advanced level of computer literacy and an important ability that modern citizens should possess.

While seriously advocating computational thinking, programming is emphasized in the elementary school and high school computer curricula. Scratch, a visual programming environment, is widely used for entry level computer classes. Scratch (http://Scratch.mit.edu/) is an educational programming language developed in the Lifelong and Kindergarten group at the MIT Media Lab. The design of Scratch aims to enable the participation of students of various ages, genders and races.

In order to better analyze students' performances in terms of computational thinking, Brennan \& Resnick [3] designed a framework of analysis. They claim that computational thinking can be evaluated in three aspects: computational thinking concepts, computational thinking practices, and computational thinking perspectives. Computational thinking concepts refer to important programming concepts such as sequences, loops, parallelism, events, conditionals, operators and data.
Recruiting 36 elementary school students in a Scratch camp as participants, Hsu found that both girls and boys improved significantly in their programming concepts, which means that both girls and boys benefit from the learning activity [4]. In the study above, gender did not present any differences in terms of the learning of computational concepts. However, the number of female participants was about half that of male students.

As this study addresses gender differences in game design, the aspect of game design styles is considered. Gender differences are revealed in game genres, game worlds, player characters and feedback. Female students tend to create instructional games in realistic worlds, and use "you" to address the player, while male students tend to create adventure games in fantasy worlds, give players specific names and give violent feedback [5]. Moreover, Hsu [6] examined eight 2 nd graders and found that girls were more interested in multimedia and realistic characters while boys were more interested in programming interactions and fantasy characters. Furthermore, girls were found to create more characters, character sounds and self-made characters than boys, while boys tended to revise backgrounds [4]. When designing games, boys tended to incorporate negative reinforcement, while girls tended to use both positive and negative reinforcements.

In sum, female students seem to possess the same programming concepts as male students; however, they differ in participation and game design styles.

\section{Purpose of the Study}

The purpose of this project was to understand elementary students' gender preferences in interactive game design. In order to achieve the research purpose, four major research questions were generated.

1) Are there any gender differences in terms of computational concepts?

2) Are there any gender differences in terms of use of multimedia?

3) Are there any gender differences in terms of use of codes?

4) Are there any gender differences in terms of game design styles?

This study was carried out in the setting of a Scratch competition in 2013. The Scratch design competition occurred from 9:00 in the morning to 15:00 in the afternoon, lasting for 6 hours. In total, there were 46 participants, with 29 male

\footnotetext{
* This work was supported by the National Science Council, Taiwan, ROC, under Project NSC 102-2511-S-431-003.
} 
students and 17 female students. Recommended by their elementary school teachers, the participants were considered to be skilled at Scratch game design. Each team had two students. There were 23 teams, 13 teams of males, 7 teams of females and 3 mixed teams (with one boy and one girl). The goal of the competition was to design a game that would raise awareness of environment protection, which is considered neutral in terms of gender. The participants did not know the goal of the competition until it was launched.

\section{Method}

Questionnaires and work analysis were utilized as two major data collection methods. Developed by the researcher, the questionnaire was used to test students' computational concepts including sequences, loops, parallelism, events, conditionals, operators, data and sensing. Each question item was designed in the context of Scratch. Figure 1 is an example of the sequence concept. Students were required to predict what the character would do when the green flag was clicked. In total, there were 9 question items. The questionnaire was administered at the end of the competition. In total, 46 copies were collected.

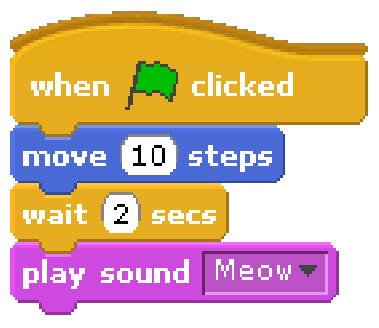

Fig. 1 Example of sequence.

The students' results were collected after the competition. All of the 23 games were collected. The works were later analyzed using Scrape (http://happyanalyzing.com/), a project created by RiverSound Media and funded through the National Science Foundation (see Fig. 2). Two raters were in charge of coding the data. When discrepancies occurred, the raters would discuss the matter and come to an agreement.

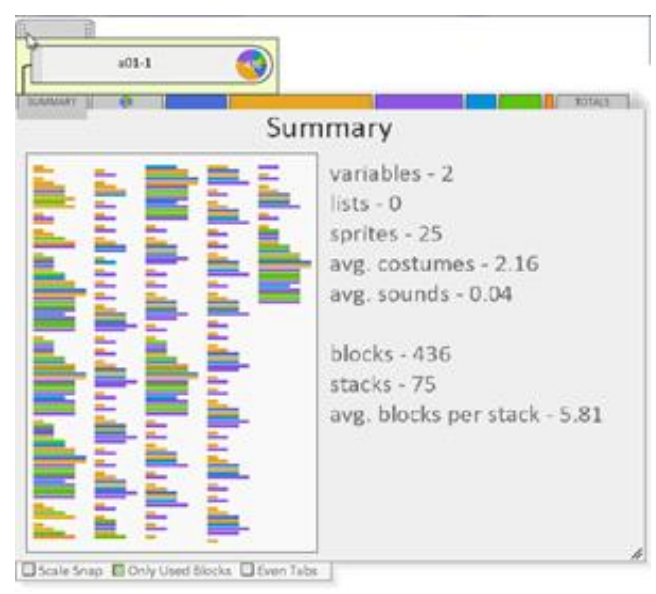

Fig. 2 Snapshot of Scrape.

\section{Results}

The results are reported to address the four research questions.

\section{A. Computational concepts}

Based upon the collected questionnaires, an independentsamples t-test was conducted to compare the means of the male and female groups. An alpha level of .05 was used for all statistical tests. The results, as shown in Table I, indicated that there was a significant difference in the total score for the male groups $(\mathrm{M}=6.34, \mathrm{SD}=1.72)$ and the female groups $(\mathrm{M}=6.18$, $\mathrm{SD}=1.67), \mathrm{t}(46)=.324, \mathrm{p}=.747>.05$. Females were found to have significantly better knowledge of counting loops than males, $\mathrm{t}(46)=2.73, \mathrm{p}=.028<.05$.

TABLE I t-test Results of Questionnaire on Computational Concepts

\begin{tabular}{|c|c|c|c|c|c|}
\hline Concepts & Gender & $\mathrm{n}$ & Mean & SD & $\mathrm{t}$ \\
\hline \multirow{2}{*}{ Sequences } & Male & 29 & .90 & .310 & \multirow{2}{*}{-1.797} \\
\hline & Female & 17 & 1.00 & .000 & \\
\hline \multirow{2}{*}{$\begin{array}{c}\text { Conditional } \\
\text { Loops }\end{array}$} & Male & 29 & .48 & .509 & \multirow{2}{*}{.078} \\
\hline & Female & 17 & .47 & .514 & \\
\hline \multirow{2}{*}{$\begin{array}{l}\text { Counting } \\
\text { Loops }\end{array}$} & Male & 29 & .76 & .435 & \multirow{2}{*}{$-2.985^{*}$} \\
\hline & Female & 17 & 1.00 & .000 & \\
\hline \multirow{2}{*}{ Sensing } & Male & 29 & .83 & .384 & \multirow{2}{*}{.954} \\
\hline & Female & 17 & .71 & .470 & \\
\hline \multirow{2}{*}{ Parallelism } & Male & 29 & .79 & .412 & \multirow{2}{*}{1.079} \\
\hline & Female & 17 & .65 & .493 & \\
\hline \multirow{2}{*}{ Events } & Male & 29 & .90 & .310 & \multirow{2}{*}{1.093} \\
\hline & Female & 17 & .76 & .437 & \\
\hline \multirow{2}{*}{ Conditionals } & Male & 29 & .86 & .351 & \multirow{2}{*}{.334} \\
\hline & Female & 17 & .82 & .393 & \\
\hline \multirow{2}{*}{ Operators } & Male & 29 & .45 & .506 & \multirow{2}{*}{-.522} \\
\hline & Female & 17 & .53 & .514 & \\
\hline \multirow{2}{*}{ Data } & Male & 29 & .38 & .494 & \multirow{2}{*}{1.027} \\
\hline & Female & 17 & .24 & .437 & \\
\hline \multirow{2}{*}{ Total } & Male & 29 & 6.34 & 1.72 & \multirow{2}{*}{.324} \\
\hline & Female & 17 & 6.18 & 1.67 & \\
\hline
\end{tabular}

${ }^{*}$ Significance at .05 level

\section{B. Use of Multimedia}

In total, 20 designs by students, 13 male teams and 7 female teams, were collected and analyzed. In order to make sure that the groups did not differ in their computational concepts, an independent-samples t-test was conducted and found that there was no significant difference in the total score for the male groups $(\mathrm{M}=6.46, \mathrm{SD}=1.68)$ and the female groups $(\mathrm{M}=6.21, \mathrm{SD}=1.84), \mathrm{t}(40)=.429, \mathrm{p}=.67>.05$.

A comparison of the use of multimedia was measured in terms of the amount and the nature of backgrounds, audio clips 
and characters. Since a Scratch project can have many backgrounds, students can decide if they want to use the builtin backgrounds, revise the built-in backgrounds, or create their own backgrounds. Similarly, students can choose characters, and characters may have many costumes. As seen in Table II, males were found to use significantly more built-in costumes for characters than females, $\mathrm{t}(20)=2.212, \mathrm{p}<.05$. The above finding was similar to Hsu's [6] in that boys tended to use more built-in characters. Though females in this study used more backgrounds and costumes than males, the difference of the means was not significant.

TABLE II t-test Results of Background and Costume Types

\begin{tabular}{|c|c|c|c|c|c|}
\hline Type & Gender & $\mathrm{n}$ & Mean & ST & $\mathrm{t}$ \\
\hline \multirow{2}{*}{$\begin{array}{l}\text { Use Built-in } \\
\text { Backgrounds }\end{array}$} & Male & 13 & .77 & 1.092 & \multirow{2}{*}{.422} \\
\hline & Female & 7 & .57 & .787 & \\
\hline \multirow{2}{*}{$\begin{array}{l}\text { Revise Built- } \\
\text { in Background }\end{array}$} & Male & 13 & 1.62 & 2.364 & \multirow{2}{*}{1.952} \\
\hline & Female & 7 & .29 & .488 & \\
\hline \multirow{2}{*}{$\begin{array}{l}\text { Create New } \\
\text { Background }\end{array}$} & Male & 13 & 1.92 & 2.326 & \multirow{2}{*}{-1.196} \\
\hline & Female & 7 & 3.29 & 2.628 & \\
\hline \multirow{2}{*}{$\begin{array}{l}\text { Total No of } \\
\text { Background }\end{array}$} & Male & 13 & 4.31 & 1.888 & \multirow{2}{*}{.169} \\
\hline & Female & 7 & 4.14 & 2.410 & \\
\hline \multirow{2}{*}{$\begin{array}{l}\text { Use Built-in } \\
\text { Costumes }\end{array}$} & Male & 13 & 6.92 & 9.682 & \multirow{2}{*}{$2.212^{*}$} \\
\hline & Female & 7 & .86 & 1.464 & \\
\hline \multirow{2}{*}{$\begin{array}{l}\text { Revise Built- } \\
\text { in Costumes }\end{array}$} & Male & 13 & 1.85 & 2.375 & \multirow{2}{*}{.641} \\
\hline & Female & 7 & 1.14 & 2.268 & \\
\hline \multirow{2}{*}{$\begin{array}{l}\text { Create New } \\
\text { Costumes }\end{array}$} & Male & 13 & 8.92 & 8.490 & \multirow{2}{*}{-.454} \\
\hline & Female & 7 & 10.57 & 5.996 & \\
\hline \multirow{2}{*}{$\begin{array}{c}\text { Total No of } \\
\text { Costume }\end{array}$} & Male & 13 & 17.69 & 9.978 & \multirow{2}{*}{1.225} \\
\hline & Female & 7 & 12.57 & 6.268 & \\
\hline
\end{tabular}

${ }^{*}$ Significance at .05 level

Due to the fact that the students were given microphones and headphones to use in the competition, they were able not only to use built-in audio clips but also to create their own recordings. The students were not, however, offered the use of any audio editing software. None of them revised the sound clips. According to the analysis, there was no significant difference in terms of their use of audio clips.

\section{Use of Codes}

There are 8 types of code blocks, including motion, looks, sound, pen, control, sensing, operators and variables. Students utilize various code blocks to make their works interactive. The student designs were analyzed in terms of the amount and the variety in their code blocks. According to Table III, there were no significant gender differences in terms of the amounts of variables, blocks and stacks.

The occurrences of 8 types of code blocks were not significantly different among groups. According to Table IV, there was a significant difference in the variety of sensing code blocks for the male groups $(\mathrm{M}=3.00, \mathrm{SD}=.913)$ and the female groups $(\mathrm{M}=2.00, \mathrm{SD}=.816), \mathrm{t}(20)=2.419, \mathrm{p}=.026>.05$.

TABLE III t-test Results of Variables, Blocks and Stacks

\begin{tabular}{|c|c|c|c|c|c|}
\hline & Gender & $\mathrm{N}$ & Mean & ST & $\mathrm{T}$ \\
\hline \multirow{2}{*}{ Variables } & Male & 13 & 2.46 & 1.050 & \multirow{2}{*}{.621} \\
\cline { 2 - 5 } & Female & 7 & 2.00 & 2.309 & \\
\hline \multirow{2}{*}{ Blocks } & Male & 13 & 315.85 & 187.629 & \multirow{2}{*}{1.566} \\
\cline { 2 - 5 } & Female & 7 & 195.86 & 98.886 & \\
\hline \multirow{2}{*}{ Stacks } & Male & 13 & 57.31 & 31.972 & \multirow{2}{*}{1.612} \\
\cline { 2 - 5 } & Female & 7 & 36.29 & 16.670 & \\
\hline
\end{tabular}

TABLE IV t-test Results of the Varieties of 8 Types of Code Blocks

\begin{tabular}{|c|c|c|c|c|c|}
\hline Amount & Gender & $\mathrm{n}$ & Mean & ST & $\mathrm{t}$ \\
\hline \multirow{2}{*}{ Motion } & Male & 13 & 4.38 & 1.557 & \multirow{2}{*}{1.285} \\
\hline & Female & 7 & 3.57 & .787 & \\
\hline \multirow{2}{*}{ Control } & Male & 13 & 8.69 & 1.494 & \multirow{2}{*}{1.495} \\
\hline & Female & 7 & 7.43 & 2.299 & \\
\hline \multirow{2}{*}{ Looks } & Male & 13 & 5.38 & 1.387 & \multirow{2}{*}{1.098} \\
\hline & Female & 7 & 4.71 & 1.113 & \\
\hline \multirow{2}{*}{ Sensing } & Male & 13 & 3.00 & .913 & \multirow{2}{*}{$2.419^{*}$} \\
\hline & Female & 7 & 2.00 & .816 & \\
\hline \multirow{2}{*}{ Sound } & Male & 13 & .92 & .760 & \multirow{2}{*}{.174} \\
\hline & Female & 7 & .86 & .900 & \\
\hline \multirow{2}{*}{ Operators } & Male & 13 & 3.46 & 1.506 & \multirow{2}{*}{1.592} \\
\hline & Female & 7 & 2.29 & 1.704 & \\
\hline \multirow{2}{*}{ Pen } & Male & 13 & .31 & 1.109 & \multirow{2}{*}{-.632} \\
\hline & Female & 7 & .71 & 1.496 & \\
\hline \multirow{2}{*}{ Variables } & Male & 13 & 2.38 & .768 & \multirow{2}{*}{.896} \\
\hline & Female & 7 & 2.00 & 1.155 & \\
\hline
\end{tabular}

\section{Game Design Styles}

Game design styles were analyzed according to the uses of counting score, counting time, level progression and feedback. For example, Fig. 3 is a trash collection game in which the user needs to lead Scratch to collect trash. If Scratch touches the trash, one point will be added. As soon as the user acquires a certain number of points, he/she will progress to the next level. In this game, therefore, the game makers used the mechanism of counting points, level progression and positive feedback. According to Table V, the male students seemed to use more game design mechanisms in their projects than the female students. As far as feedback types are concerned, only one female group did not use any feedback in their project. The female students tended to use positive feedback (57.1\%), while the male students tended to use negative feedback $(46.2 \%)$ and positive and negative feedback (46.2\%) as indicated in Table VI. 


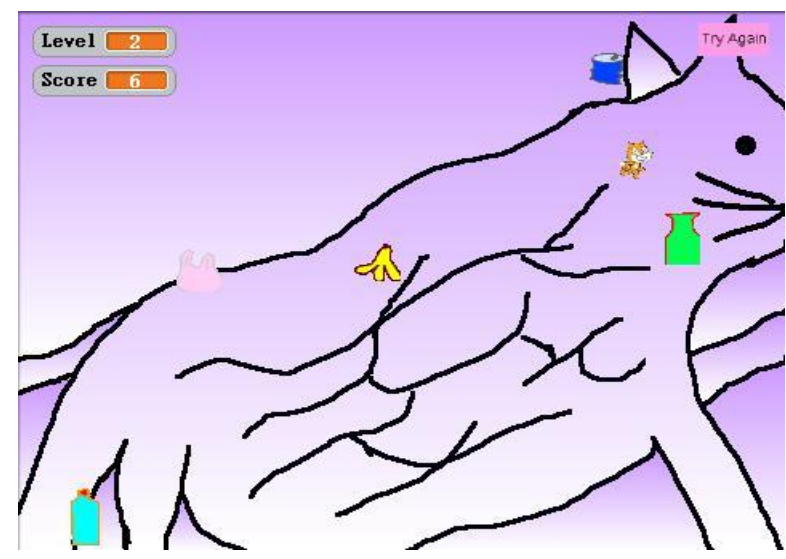

Fig. 3 Snapshot of a Trash Collection Game.

TABLE V Percentages of Usages of Game Design Styles

\begin{tabular}{|c|c|c|c|}
\hline Design Styles & Gender & N & Percentage \\
\hline \multirow{2}{*}{ Counting Score } & Male & 13 & $100 \%$ \\
\cline { 2 - 4 } & Female & 6 & $85.7 \%$ \\
\hline \multirow{2}{*}{ Counting Time } & Male & 3 & $23.1 \%$ \\
\cline { 2 - 4 } & Female & 1 & $14.3 \%$ \\
\hline \multirow{2}{*}{ Level Progression } & Male & 7 & $53.8 \%$ \\
\cline { 2 - 4 } & Female & 3 & $42.9 \%$ \\
\hline
\end{tabular}

TABLE VI Percentages of Feedback Types

\begin{tabular}{|c|c|c|c|}
\hline \multirow{2}{*}{ Feedback } & Gender & N & Percentage \\
\hline \multirow{2}{*}{ None } & Male & 0 & $0 \%$ \\
\cline { 2 - 4 } & Female & 1 & $14.3 \%$ \\
\hline \multirow{2}{*}{ Positive } & Male & 6 & $46.2 \%$ \\
\cline { 2 - 4 } & Female & 4 & $57.1 \%$ \\
\hline \multirow{2}{*}{ Negative } & Male & 1 & $7.7 \%$ \\
\cline { 2 - 4 } & Female & 1 & $14.3 \%$ \\
\hline \multirow{2}{*}{ Positive and Negative } & Male & 6 & $46.2 \%$ \\
\cline { 2 - 4 } & Female & 1 & $14.3 \%$ \\
\hline
\end{tabular}

\section{Discussions and Recommendations}

According to the results of this study, it seems that there are no significant differences in the total score of computational concepts between the male groups and the female groups. But girls performed better at the concept of counting loops. As the study was carried out in the setting of a contest, computational ability was considered to be the main reason that these students were selected to take part in the competition. All of the participants were identified as being skilled at Scratch game design. But there was still a gender participation gap. The number of female participants were about half that of male participants. Sexual differentiation seems to occur early in elementary schools. Efforts should be made to increase the equality of gender participation in technology.

The students incorporated various multimedia into their projects. Hsu [4] reported that students may utilize different completion strategies in different instructional settings. Due to the fact that these designs were made in a competitive setting, the students might employ strategies in order to win prizes. The results indicate that the male student groups used more built-in costumes for their characters. This finding is similar to Hsu [6] in that male students tended to focus on interaction and thus spent less time on drawing costumes.

The number and variety of code blocks were analyzed. The male student groups used more diverse sensing blocks than the female student groups. Since the participants of this study were expected to possess good computational thinking, their use of code blocks seemed to be rather fluent. All projects have similar numbers of blocks and stacks.

As far as game design styles are concerned, the participants used the mechanisms of score counting, time counting, level progression and feedback in their projects. Both boys' groups and girls' groups used the score counting mechanism the most; the participants used time counting the least. This may be due to the fact that time counting would involve the creation and use of variables, which may not be familiar to elementary school students. It would be interesting to conduct qualitative studies to explore gender preferences in game design styles.

\section{References}

[1] J. Wing, "Computational thinking," Communications of the ACM, vol. 49, no. 3, pp. 33-35, March 2006.

[2] Computer Science Teachers Association, Computational Thinking in $K$ 12 Education: Teacher Resources, 2011. Available at http://csta.acm.org/Curriculum/sub/CurrFiles/472.11CTTeacherResource s_2ed-SP-vF.pdf.

[3] K. Brennan, and M. Resnick, "New frameworks for studying and assessing the development of computational thinking," presented at the American Educational Research Association, 2012.

[4] H. Hsu, "Elementary School Students' Gender Differences in Game Design Activities," in Proc. International Conference on Building Allround Success, pp. 311-332, December 2013.

[5] Y. Kafai, "Gender differences in children's constructions of video games," in P. Greenfield and R. Cocking, Eds., Interacting With Video, Norwood, NJ: Ablex Publishing Corporation, 1996, pp. 39-66.

[6] H. Hsu, "Gender Differences in Elementary School Students' Game Design Preferences," International Journal of Information and Education Technology, vol. 3, no. 2, pp. 172-176, 2013. 